\title{
Early prone position for COVID-19 patients with severe hypoxia: reduces the mortality but increases the intubation risk?
}

\author{
Aline Almeida Gulart ${ }^{*}$ (I0 and Isabela Julia Cristiana Santos Silva ${ }^{1,2}$
}

(C) 2020 Springer-Verlag GmbH Germany, part of Springer Nature

\section{Dear Editor,}

We have read with interest the study by Zang et al. [1] recently published in Intensive Care Medicine, which showed greater 90-day survival in the group of nonintubated COVID-19 patients with severe hypoxia who performed early prone position (56.5\%) compared to the group who did not (24.3\%). This result is an important differential in relation to the several studies previously published. The study was the first to show improvement in a clinically relevant outcome, in addition to the reduction in hypoxia and respiratory rate already demonstrated previously [2-4].

Therefore, we were very intrigued by a result seen in the supplementary material, not mentioned in the main text by the authors. Although there is not a significant difference, we found in Table S3 [1] that a greater number of patients in the early prone position group required invasive mechanical ventilation (34.8\%) when compared to the non-prone position group (10.8\%). However, what draws the most attention is that many patients who died in the non-prone position group did not receive invasive mechanical ventilation (Table S2-88.9\%) [1]. What is the explanation for that? Usually, patients with more severe ARDS need endotracheal intubation and invasive mechanical ventilation. Was the tracheal intubation of these patients not considered due to any severity criterion not reported by the authors? Is non-intubation a cause associated with high mortality in the non-prone position group?

\footnotetext{
*Correspondence: aline.gulart@hotmail.com

${ }^{1}$ Physiotherapist in the Intensive Care Unit of the Cardiology Institute of Santa Catarina, Sao Jose, SC, Brazil
}

Full author information is available at the end of the article
This is an important discussion, since one of the main concerns regarding the use of awake prone position is whether it actually prevents intubation and the damage associated with invasive mechanical ventilation or if it simply delays intubation. Although the ideal time for intubation and mechanical ventilation for patients with ARDS is not known, delayed intubation has been associated with increased mortality in these patients [5]. Ding et al. [3] demonstrated more severe hypoxia in patients who were intubated despite early prone position when compared to patients who performed awake prone position and did not require intubation. Thus, the authors suggested the application of early prone position especially in patients with moderate ARDS and baseline $\mathrm{SpO}_{2}>95 \%$. Controversially, the patients selected by Zang et al. [1] had severe hypoxia.

Finally, an important limitation not mentioned by the authors is the possibility of methodological bias since the method in which patients were allocated to the groups was not described. Although we recognize the importance of the study by Zang et al. [1], we hope that results from ongoing randomized controlled trials (e.g., NCT04383613, NCT04359797, NCT04350723, NCT04347941, NCT04477655 and NCT04344587) demonstrate greater certainty about the effects of the early prone position in non-intubated COVID-19 patients with hypoxia on intubation and mortality rates.

\footnotetext{
Author details

${ }^{1}$ Physiotherapist in the Intensive Care Unit of the Cardiology Institute of Santa Catarina, Sao Jose, SC, Brazil. ${ }^{2}$ Graduate Program in Physical Therapy, Centro de Ciências da Saúde e do Esporte (CEFID), Universidade do Estado de Santa Catarina (UDESC), Florianópolis, SC, Brazil.
} 


\section{Funding}

Not applicable.

\section{Compliance with ethical standards}

\section{Conflicts of interest}

The authors declared that they have no conflict of interest.

Ethical approval

Not applicable.

\section{Publisher's Note}

Springer Nature remains neutral with regard to jurisdictional claims in published maps and institutional affiliations.

\section{Accepted: 7 August 2020}

Published online: 20 August 2020

\section{References}

1. Zang X, Wang Q, Zhou H, Liu S, Xue X, Group C-EPPS (2020) Efficacy of early prone position for COVID-19 patients with severe hypoxia: a single-center prospective cohort study. Intensive Care Med. https://doi. org/10.1007/s00134-020-06182-4

2. Sartini C, Tresoldi M, Scarpellini P, Tettamanti A, Carco F, Landoni G, Zangrillo A (2020) Respiratory parameters in patients with COVID-19 after using noninvasive ventilation in the prone position outside the intensive care unit. JAMA. https://doi.org/10.1001/jama.2020.7861

3. Ding L, Wang L, Ma W, He H (2020) Efficacy and safety of early prone positioning combined with HFNC or NIV in moderate to severe ARDS: a multi-center prospective cohort study. Crit Care 24(1):28. https://doi. org/10.1186/s13054-020-2738-5

4. Coppo A, Bellani G, Winterton D, Di Pierro M, Soria A, Faverio P, Cairo M, Mori S, Messinesi G, Contro E, Bonfanti P, Benini A, Valsecchi MG, Antolini L, Foti G (2020) Feasibility and physiological effects of prone positioning in non-intubated patients with acute respiratory failure due to COVID-19 (PRON-COVID): a prospective cohort study. Lancet Respir Med. https:// doi.org/10.1016/S2213-2600(20)30268-X

5. Kangelaris KN, Ware LB, Wang CY, Janz DR, Zhuo H, Matthay MA, Calfee CS (2016) Timing of intubation and clinical outcomes in adults with acute respiratory distress syndrome. Crit Care Med 44(1):120-129. https://doi. org/10.1097/CCM.0000000000001359 